\title{
CARTOGRAFIAS DA CIDADE (IN)VISÍVEL: SETORES POPULARES, CULTURA ESCRITA, EDUCAÇÃO E LEITURA NO RIO DE JANEIRO IMPERIAL
}

\section{RESENHA}

VENÂNCIO, G. M.; SECRETO, M. V.; RIBEIRO, G. S. (org.).

Cartografias da cidade (in)visível: setores populares, cultura escrita, educação e leitura no Rio de Janeiro imperial.

Rio de Janeiro: Mauad X: Faperj, 2017.

\section{Giuslane Francisca da Silva ${ }^{1}$}

lattes.cnpq.br/3394251044954546

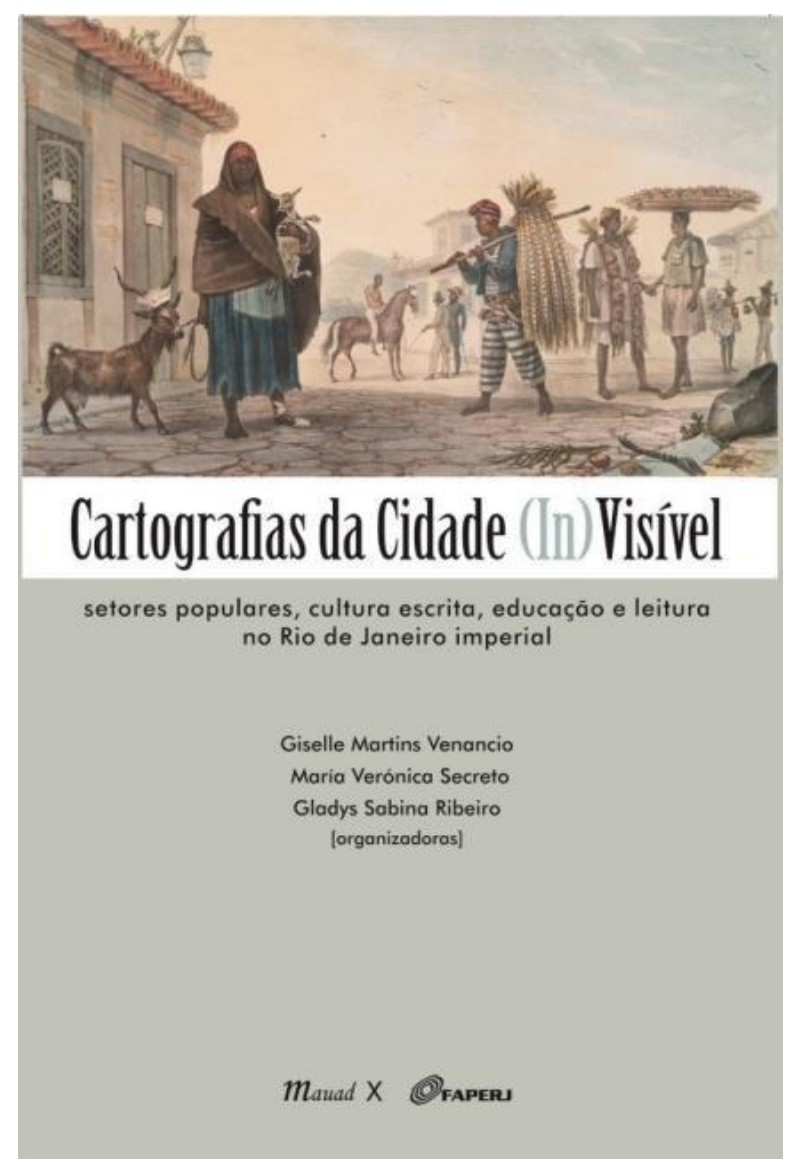

A obra Cartografias da cidade (in)visível: setores populares, cultura escrita, educação e leitura no Rio de Janeiro imperial é organizada por Giselle Venâncio, Maria Secreta e Gladys Ribeiro. Está dividida em duas partes e é composta por um total de onze textos escritos por pesquisadores de instituições distintas.

Cada texto traz abordagens inovadoras, visto que resgatam aspectos da cidade do Rio de Janeiro, muitas vezes relegados pelos pesquisadores, ao mesmo tempo em que desconstroem a ideia de que as camadas populares estavam distanciadas ou mesmo excluídas do mundo

\footnotetext{
${ }^{1}$ Doutoranda em Educação na Universidade do Estado do Rio de Janeiro (Brasil). Contato: giuslanesilva@hotmail.com.
} 
letrado. Para tanto, “cartografar um Rio de Janeiro ainda invisível” (SECRETO; VENANCIO, 2017, p. 9) constitui o objetivo central da obra.

A partir de fontes como os periódicos, os autores mostram que muitos populares na cidade do Rio de Janeiro Imperial tinham acesso à cultura escrita. Ampliando os sujeitos de suas pesquisas, os autores demonstram que escravos, forros, migrantes pobres, estiveram de alguma forma expostos a cultura escrita. É possível conjecturar que casos assim podem ter ocorrido em outras cidades também.

O livro está dividido em duas partes, a primeira delas, "Usos populares da leitura e escrita", reúne quatro textos em torno dessa temática. A segunda parte, "Práticas educativas de populares no Rio de Janeiro oitocentista”, agrega um total de sete artigos. Para uma melhor explicitação do livro como um todo, realizo uma breve análise de cada um dos textos.

No primeiro texto, "Em primeira pessoa", de Giselle Venancio, a autora vai analisar a carta que a liberta, Maria Rosa, escreveu à Princesa Isabel na ocasião de seu aniversário quando era comum alforriar alguns escravos. A carta assinada por Maria Rosa solicitava à Imperatriz que interviesse junto à Câmara Municipal para que sua filha, Ludovina, que era mãe de três filhos, fosse alforriada. Os dados que a autora levantou demonstram que escravos e libertos eram alfabetizados e não muito raro investiam também na formação de seus filhos.

No segundo capítulo, "Posta em cena: educação moral e estética e heterogeneidade social e teatro oitocentista”, cujas autoras são María Secreto e Viviana Gelado, a abordagem recai sobre o letramento popular e/ou negro na cidade do Rio de Janeiro, a partir de um ângulo não muito casual: o teatro, visto como mecanismo de educação moral e estética do público carioca.

Segundo as autoras, não sendo o escravo doméstico e especialmente o urbano, almejado pela cidade das letras, via no teatro a chance de depreender uma moral pragmática, assim como também lições de retórica e boas maneiras que "poderiam coadunar para desobstruir o improvável caminho da ascensão social dentro dos limites jurídicos impostos” (SECRETO; GELADO, 2017, p. 44-45). 
Em "Saber ler, contar e poupar: reflexões entre economia popular e cultura letrada no Rio de Janeiro, 1831/1864”, de Luiz Saraiva e Rita de Cássia Almico, os autores partem de um consenso da historiografia brasileira, o de que as camadas mais baixas da sociedade teriam tido acesso limitado ao mercado financeiro, além do que a baixa circulação financeira teria restringido os trabalhadores pobres e escravos dos conhecimentos mais "sofisticados no âmbito da economia e de uma monetarização crescente" (SECRETO; GELADO, 2017, p. 49), a exemplo do que aconteceu no Rio de Janeiro no decorrer do século XX. Partindo desse ponto, os autores apresentam evidências de um maior protagonismo das camadas populares em atividades ligadas aos setores financeiros, destacam ainda o impacto dessas atuações na economia da cidade.

A partir de anúncios de jornais, os autores levantaram a hipótese de que havia um mercado de bens financeiros e que poderia ser usado por setores populares. Ressaltam também a importância da economia popular para a cidade.

Carlos Eduardo Villa, em "Escrever como curso de transação dos pequenos agentes do Rio de Janeiro na metade do século XX”, parte de dados cartoriais e evidencia que a cultura escrita aumentou consideravelmente ao longo do século XIX, o que leva crer que houve um aumento também dos grupos alfabetizados. Outra defesa do autor é que o aumento de trabalhadores, que ofertavam seus serviços nos jornais que circulavam na cidade, permite afirmar também que houve um incremento da cultura escrita entre os populares.

O texto "Ler, escrever e contar: cartografias da escolarização e práticas educativas no Rio de Janeiro oitocentista", de Alessandra Shueler e Irma Rizzini, abre a segunda parte do livro. Nele, as autoras trazem questões ainda pouco debatidas e/ou conhecidas pelos historiadores, pois afirmam que a população pobre e seus filhos, assim como os negros, compunham o grupo escolar da cidade, isto é, frequentavam escolas e que, portanto, uma parcela de populares era alfabetizada.

As pesquisas das autoras contrariam uma ideia durante muito tempo hegemônica na historiografia, a de que não havia escolas noturnas e ensino primário voltado ao atendimento do público trabalhador, além de 
desmitificar a clássica afirmação de que grande parte da população brasileira no Brasil oitocentista era analfabeta, como se vê, essa não é a realidade da cidade do Rio de Janeiro. O trabalho dessas autoras e alguns outros desconstroem totalmente essas ideias.

Em "Educação no Rio de Janeiro joanino nas páginas da Gazeta do Rio de Janeiro: espaços abertos para a mobilidade social”, Camila Borges da Silva numa perspectiva que se aproxima do artigo anterior, analisa o formato dos espaços educacionais durante a presença da Corte no Brasil. Ela explora também como as aulas noturnas abriam condições de ascensão social às camadas intermediárias da sociedade, formadas em sua maioria por pardos, mulatos e portugueses pobres (SILVA, 2017).

Jonis Freire e Karoline Karula, em "Camadas populares e higienismo no Rio de Janeiro em fins dos anos de 1870", analisam um grupo social composto por alunos que frequentavam a Escola Noturna da Lagoa, na cidade do Rio de Janeiro, no final da década de 1870. Nessa escola foram ofertadas conferências sobre higiene popular, o curioso é que grande parte do público que frequentava essas conferências era composto por alunos dessa instituição. As autoras, levando em consideração o fato de que essas conferências ocorriam nos dias em que não havia aula, afirmam que é muito provável que esses alunos iam porque o assunto lhes interessava.

Em "Cidade solidária: beneficência educacional no cotidiano popular da Corte Imperial”, de Marconni Marotta, discute-se a instrução popular financiada por associações, com destaque para a Sociedade Jovial e Instrutiva. Aponta também algumas políticas públicas voltadas para a educação primária das camadas populares.

No texto "Aulas do Comércio: mundo da educação versus mundo do trabalho livre e pobre na cidade do Rio de Janeiro", Gladys Sabina Ribeiro e Paulo Cruz Terra analisam as aulas do Comércio e o mundo do trabalho na cidade do Rio de Janeiro. Eles enfatizam também as transformações sofridas pela instituição a partir da data de sua fundação até a Reforma de 1854 .

Tomando uma instituição de ensino como enfoque de seu trabalho, Alexandro Paixão, em “A educação popular no Rio de Janeiro oitocentista: 
o caso do Liceu Literário Português (1860-1880)”, discute os primeiros anos do Liceu Literário Português do Rio de Janeiro.

A presente instituição foi fundada no ano de 1868 sob os auspícios de alguns membros do Gabinete Português de Leitura e tinha por objetivo atender os ideais de "'comunidade' relacionados à questão da cultura portuguesa, filantropia e instrução popular” (PAIXÃO, 2017, p. 215) no Rio de Janeiro. Foi talvez a primeira instituição na capital do Império a oferecer cursos noturnos gratuitos de instrução primária.

O Liceu também oferecia aulas de comércio para jovens e adultos que se mostrassem interessados na aprendizagem e no trabalho, logo em seguida passava a compor a classe caixeiral, muito comum naquele momento. Entre os anos de 1868 a 1884, o Liceu formou cerca de 6.500 alunos.

O autor destaca a fundação de uma escola noturna que atendia jovens e adultos que não podiam frequentar escolas em outros horários. A escola era mantida pelo Gabinete Português. Há também a citação de outra instituição, o Collegio Victorio da Costa, com o externato para meninos pobres, de propriedade de um dos membros do gabinete.

O último texto "Pelos caminhos da liberdade: sujeitos, espaços e práticas educativas (1880-1888)", Alexandra Lima da Silva e Ana Chrystina Mignot abordam as iniciativas de educação de escravos e libertos, bem como ressaltam o papel do Centro Abolicionista Ferreira de Menezes, que foi criado por funcionários do jornal Gazeta da Tarde e que era, então, dirigido por José do Patrocínio, uma importante figura dentro do movimento abolicionista.

Essa perspectiva, defendem as autoras, alarga a compreensão sobre a educação de cativos e libertos para além das escassas escolas que existiam Brasil afora. O Centro Abolicionista, além de abrir e manter escolas primárias noturnas, promovia outras atividades como festas, espetáculos teatrais, musicais etc.

Através da análise de diversos periódicos que circulavam na cidade, as autoras encontraram várias escolas gratuitas que instruíam "menores e adultos livres, libertos e escravos, sem distinção de cor, nacionalidade ou religião" (SILVA; MIGNOT, 2017, p. 245). 
Ao analisarem as ações do Centro Abolicionista Ferreira de Menezes, as autoras trouxeram à tona nomes como José do Patrocínio, José Ferreira de Menezes, Israel Soares, dentre outros, que compunham o quadro dos membros do movimento abolicionista. Ressaltam também que figuras como essas, ao escreverem em jornais, pretendiam conquistar a simpatia das elites para benefício de suas causas. No entanto, escreviam também para muitos libertos e descendentes de escravos que possuíam acesso a esses escritos.

Os textos que compõem a obra discutida aqui, com uma linguagem clara e objetiva, levantam questionamentos e desconstroem muitos mitos que se firmaram na historiografia brasileira, no caso específico, o de que as camadas populares no oitocentos estiveram alheias à cultura escrita, ou que sequer entendiam o valor da educação. É justamente isso que os textos buscam desmistificar ao mostrar que havia escolas noturnas, muitas delas mantidas por associações de dentro do movimento abolicionista. Tais escolas eram voltadas ao atendimento de trabalhadores, escravos e libertos, consequentemente uma parcela significativa de populares estavam inseridos no universo da cultura escrita e que, portanto, eram alfabetizados.

Recebido em 12 de maio de 2018. Aprovado em 23 de maio de 2018. 